\title{
Sensitivity of the West African hydrological cycle in ORCHIDEE to infiltration processes
}

\author{
T. d'Orgeval ${ }^{1}$, J. Polcher ${ }^{2}$, and P. de Rosnay ${ }^{3}$ \\ ${ }^{1}$ UPMC/LMD, Paris, France (Université Pierre et Marie Curie / Laboratoire de Météorologie Dynamique) \\ ${ }^{2}$ CNRS/LMD, Paris, France (Centre National de la Recherche Scientifique / Laboratoire de Météorologie Dynamique) \\ ${ }^{3}$ CNRS/CESBIO, Toulouse, France (Centre National de la Recherche Scientifique / Centre d'Etudes Spatiales de la \\ BIOsphère)
}

Received: 1 July 2008 - Published in Hydrol. Earth Syst. Sci. Discuss.: 18 August 2008

Revised: 17 November 2008 - Accepted: 17 November 2008 - Published: 15 December 2008

\begin{abstract}
The aim of this article is to test the sensitivity of the West African hydrological cycle to infiltration processes and to river reinfiltration pathways. This is done through sensitivity experiments to both inputs and paramterization settings of the ORCHIDEE Land-Surface Model. The parameterizations to take into account the effects of flat areas, ponds and floodplains on surface infiltration, and the effect of roots and deep-soil compactness on infiltration are first described. The sensitivity analysis to parameterization settings shows that the surface infiltration processes have a stronger impact in the soudano-sahelian region and more generally in semiarid African regions, whereas the rootzone and deep-soil infiltration also play a role in the guinean and intermediate regions between arid and humid ones. In the equatorial and semi-humid regions, infiltration processes generally play a minor role. The infiltration parameterizations may explain part of the difference between simulated and observed river discharge in semi-arid and intermediate basins. The sensitivity analysis to the Land-Surface Model inputs shows that different sources of uncertainty might also explain part of the error. Indeed, the precipitation forcing in the whole West African region, the long-term storage in the soudano-sahelian region, the soil types in the guinean region and the vegetation types in the equatorial region are significant sources of errors. Therefore, observations and analyses of small scale infiltration processes as well as continuous measurements of river discharges in West Africa are essential to ensure the reliability of future calibration for the infiltration parameterizations.
\end{abstract}

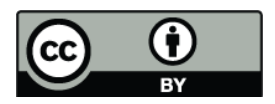

Correspondence to: T. d'Orgeval (tristan.dorgeval@lmd.jussieu.fr)

\section{Introduction}

As proposed by Guo et al. (2006), the hydrological part of the surface-atmosphere feedback loop can be divided into three elements: The occurence of precipitation $(\mathrm{P})$ changes soil moisture (SM) through the partitioning between surface runoff and infiltration (P-SM link); then increased SM favours higher evapotranspiration (ET) depending on the infiltration capacity in the soil and on the root uptake (SMET link); finally, ET may have an impact on future precipitation through a complex process (ET-P link). Guo et al. (2006) have analysed the strength of this feedback loop within the framework of the multi-model experiment GLACE (the Global Land-Atmosphere Coupling Experiment). It was shown that the global simulation of the SM-ET link is strongly variable among the different models used.

GLACE has also led to the conclusion that West Africa is one of the main hot spots of strong surface-atmosphere coupling during its rainy season (JJA) through the ET-P link (Koster et al., 2004, 2006). However, the strength of the SMET link has not been thoroughly tested and documented.

One of the aims of the African Monsoon Multidisciplinary Analysis (AMMA) project is to better understand the role of land-surface processes in the monsoon and to contribute to the development of climate models - and therefore LandSurface Models (LSM) - that better represent the surfaceatmosphere feedbacks and the SM-ET link. Recent developments in the hydrological module of the ORCHIDEE ORganising Carbon and Hydrology In Dynamic EcosystEms (Krinner et al., 2005) - LSM have focused on processes that can be critical for the representation of the SM-ET link in the West African hydrological cycle. These developments can be divided into two main categories which relates to the vertical and to the horizontal water transfers in ORCHIDEE.

Published by Copernicus Publications on behalf of the European Geosciences Union. 
The developments of the vertical water transfers focused on the physical representation of infiltration through the resolution of a diffusion equation (de Rosnay et al., 2000, 2002). The implementation of an explicit diffusion scheme allows for a detailed representation of the infiltration processes at different levels in the soil. It is therefore possible to make an accurate distinction between the effects of different types of infiltration involving surface (Peugeot et al., 2003; Cappelaere et al., 2003), rootzone and deep soil processes (Beven, 1982, 1984). Though the impact of changes in infiltration with depth was studied at different scales (Decharme et al., 2006; Chen and Kumar, 2001; Stieglitz et al., 1995), the impact on ET has not been documented at the regional scale for West Africa where the SM-ET link appears to be of such significance.

The developments of the horizontal water transfers in ORCHIDEE focused on the simulation of river flows (Ngo-Duc et al., 2007, 2005) through the parameterization of different reservoirs in a routing scheme. This allowed for the validation of ORCHIDEE against river discharges for the years 1951-2000 and the world's 10 largest river basins (Ngo-Duc et al., 2007, 2005). It showed that ORCHIDEE accurately simulates most of the largest rivers, which means that the P-SM and SM-ET links are reasonably well represented at the regional scale. A routing scheme is an interesting way to test and validate land surface processes at the regional scale. Decharme and Douville (2006) validated the outputs of 6 GSWP2 models against 80 gauging stations in 33 basins across the globe, using the TRIP (Total Runoff Integrating Pathways) routing model (Oki et al., 1999). At a smaller scale, Decharme et al. (2006) used river discharges from the Rhône-AGG database to validate new developments in the ISBA LSM. d'Orgeval and Polcher (2008) also showed that the variability of large West African river discharges over the years 1951-2000 is correctly represented by ORCHIDEE, and that precipitation changes explain the main part of this variability. However, the differences in mean absolute discharge were not analysed and the role of reinfiltration pathways such as ponds (Peugeot et al., 2003; Cappelaere et al., 2003) or floodplains (Prigent et al., 2007, 2001) in West African river basins was not thoroughly investigated.

Therefore, the aim of this article is to evaluate the largescale sensitivity of the hydrological cycle in ORCHIDEE to different infiltration processes over West Africa and to validate continental scale simulations against river discharges.

Section 2 is a description of the ORCHIDEE LSM with a special emphasis on the new infiltration parameterizations and their relevance for the West African region. Section 3 focuses on the sensitivity of evapotranspiration to surface, rootzone and deep-zone infiltration by sub-regions in West Africa. The sensitivity of large river discharges to the reinfiltration processes in river basins across Africa is presented in Sect. 4. A discussion on the validation of ORCHIDEE and ways to improve simulations follows in section 5 before the conclusions in Sect. 6.
Sections 3 and 4 use different forcing datasets because the corresponding methodologies could not be applied with both datasets. The data and methodology are therefore described in the first subsection of each section.

\section{ORCHIDEE land-surface model}

The version of ORCHIDEE used in this article works at three different scales:

- the energy balance is solved on $1^{\circ} \times 1^{\circ}$ grid boxes, which is the scale of the forcing used

- the hydrological balance is solved separately on three different tiles that make up each grid box. The size of the tiles depend on the distibution of vegetation.

- the river flows are computed through basins defined at a $0.5^{\circ} \times 0.5^{\circ}$ scale.

In this section, the hydrological module and the routing module are more specifically described.

\subsection{Hydrological module}

The hydrological module used in this article is fully described and tested in d'Orgeval (2006). It is based on developments by de Rosnay et al. (2000, 2002). Partitioning between surface infiltration and runoff is computed through a time-splitting procedure. This allows to solve the surface infiltration of precipitation with a finer timestep than $30 \mathrm{~min}-$ utes. The spatial heterogeneity of the local maximum infiltration rates is approximated by an exponential probability density distribution (Decharme and Douville, 2006; Yu, 2003). The vertical diffusion of water in the soil column is solved by the Fokker-Planck equation with Van Genuchten (1980)-Mualem (1976) parameters. Bare soil evaporation is the maximum upward hydrological flux permitted by the diffusion if this flux is inferior to potential evaporation. An adapted Monsi and Saeki (1953) law is used for bare soil evaporation under vegetation. Water extraction from roots is determined by an exponential root profile (de Rosnay and Polcher, 1998) and free drainage is the boundary condition at $2 \mathrm{~m}$ below the surface.

13 different vegetation types are defined with parameters given in Table 1. The default map is derived from the IGBP map with Olson classification (de Rosnay and Polcher, 1998). Vegetation types are grouped into 3 ensembles (bare soil, trees, and grass/crop). Transpiration and interception loss are computed separately for each vegetation type, but the induced throughfall and root uptake are aggregated per vegetation ensemble. Therefore, in each grid box, the hydrological balance is computed for three tiles corresponding to the 3 different vegetation ensembles. 3 different soil types are defined with parameters given in Table 2. The default map is derived from a dataset by Reynolds et al. (1999). The 
Table 1. Vegetation types in ORCHIDEE and main parameters: $H$ height (in $\mathrm{m}$ ), $c$ root coefficient which represents the inverse of the typical root depth (in $\mathrm{m}^{-1}$ ) (de Rosnay and Polcher, 1998), $r_{s}$ structural resistance which represents the impact of the canopy structure on the vegetation-atmosphere transfers (in $\mathrm{s} . \mathrm{m}^{-1}$ ). ${ }^{*} \mathrm{BS}=\mathrm{B}$ are Soil, $\mathrm{BL}=$ Broad-leaved, NL=Needleleaf, $\mathrm{G}=\mathrm{Grass}, \mathrm{C}=\mathrm{Crop}, \mathrm{EG}=$ Evergreen, $\mathrm{RG}=$ Raingreen.

\begin{tabular}{ccccccc}
\hline V & Ensemble & Type* & Climate & $H$ & $c$ & $r_{s}$ \\
\hline 1 & Bare soil & BS & & 0 & 0 & 0 \\
2 & Tree & BL / EG & Tropical & 45 & 0.8 & 100 \\
3 & Tree & BL / RG & Tropical & 30 & 0.8 & 75 \\
4 & Tree & NL / EG & Temperate & 20 & 1 & 50 \\
5 & Tree & BL / EG & Temperate & 20 & 0.8 & 50 \\
6 & Tree & BL / RG & Temperate & 20 & 0.8 & 50 \\
7 & Tree & NL / EG & Boreal & 15 & 1 & 50 \\
8 & Tree & BL / EG & Boreal & 15 & 1 & 50 \\
9 & Tree & NL / RG & Boreal & 15 & 0.8 & 50 \\
10 & Grass/crop & G / C3 & Temperate & 0.5 & 4.0 & 3 \\
11 & Grass/crop & G / C4 & Tropical & 0.6 & 2.5 & 5 \\
12 & Grass/crop & C / C3 & Temperate & 1.0 & 2.0 & 5 \\
13 & Grass/crop & C / C4 & Tropical & 1.0 & 2.0 & 10 \\
\hline
\end{tabular}

dominant soil type over a grid box is used for each tile in the grid box.

New parameterizations have been introduced to represent three infiltration processes (sufrace infiltration, deep-soil infiltration, rootzone infiltration) that are considered to be important to accurately represent the West African water cycle. Parameters for this version of ORCHIDEE have been fixed in accordance with validations against Hapex-Sahel observations (Goutorbe et al., 1994). More details are provided in the description of the parameterizations below and in d'Orgeval (2006).

\subsubsection{Surface infiltration}

Depending on the slope of the land surface, the surface runoff may reinfiltrate, especially through small pond systems that are common in West Africa (Peugeot et al., 2003; Cappelaere et al., 2003). In ORCHIDEE, reinfiltration is allowed in case of slopes $s$ below $s_{\max }=0.5 \%$, with reinfiltrated fraction $\gamma_{s}$ given by:

$\gamma_{s}=\max \left(0,1-\frac{s}{s_{\max }}\right)$

Integration of $\gamma_{s}$ over the grid box gives the mean reinfiltration rate for the grid box $\bar{\gamma}_{s}$. Surface intiltration parameters have been fixed in order to obtain reasonable simulations of bare soil evaporation in Hapex-Sahel observations.

\subsubsection{Deep-soil infiltration}

The compactness of the soil increases with depth $(z)$ as the smallest particles tend to percolate towards the bottom of the
Table 2. Parameters used in Van Genuchten equations for each soil type. Values are taken from Carsel and Parrish (1988) for three defined USDA soil types. $K_{S}$ is the saturated conductivity and $n$ and $\alpha$ are two parameters.

\begin{tabular}{llccc}
\hline Type & USDA name & $\begin{array}{c}K_{S} \\
\mathrm{~mm} \cdot d^{-1}\end{array}$ & $n$ & $\begin{array}{c}\alpha \\
\mathrm{m}^{-1}\end{array}$ \\
\hline Coarse & Sandy Loam & 1060.8 & 1.89 & 7.5 \\
Medium & Medium Loam & 249.6 & 1.56 & 3.6 \\
Fine & Clay Loam & 62.4 & 1.31 & 1.9 \\
\hline
\end{tabular}

soil (Beven, 1982, 1984). In ORCHIDEE, the saturated conductivity $K_{s}$ is modified in a similar way to what is done in Decharme et al. (2006). The main differences are that $K_{s}$ is constant from 0 to $z_{\lim }=0.3 \mathrm{~m}$, and can be decreased by a factor 5 at most. This factor is chosen to roughly correspond to a change of soil type from coarse to medium or medium to fine. The new conductivity profile is given by:

$K_{s}^{\prime}(z)=K_{s} \cdot \max \left(\frac{1}{5}, \min \left(1, e^{-\frac{z-z_{\text {lim }}}{z_{s}}}\right)\right)$

where $z_{s}=0.5 \mathrm{~m}$ is the characteristic depth of exponential decay for $K_{s}$ (corresponding to the same exponential decay as in Decharme et al. (2006)). In order to ensure the consistency between the values of the different parameters of the Van Genuchten formulation, $n$ and $\alpha$ are also modified with $K_{s}$. Two regressions are computed between the values of $\log (\alpha)$ and $\log \left(K_{S}\right)$, and between the values of $\log (n)$ and $\log \left(K_{S}\right)$ given by Carsel and Parrish (1988) for the 12 USDA soil types. The obtained linear models allow to compute $\alpha$ and $n$ from $K_{s}^{\prime}$. This parameterization was validated through simulations of the evapotranspiration at the end of the rainy season in the Hapex-Sahel experiment.

\subsubsection{Rootzone infiltration}

The presence of vegetation tends to increase the soil porosity in the rootzone and therefore to increase infiltration capacity (Beven, 1982, 1984). For each vegetation type $v$ on a given soil type, a multiplicative factor $K_{v}$ depending on depth $z$ is defined and the saturated conductivity is modified as follows:

$K_{v}(z)=\max \left(\left(\frac{K_{\max }}{K_{S}}\right)^{\frac{1-c_{v} z}{2}}, 1\right)$

Where $K_{\max }=7128.0 \mathrm{~mm} \cdot \mathrm{d}^{-1}$ is a constant taken as the maximum saturated conductivity value given by Carsel and Parrish (1988), $c_{v}$ is the root coefficient for vegetation type $v$ (see Table 1). The modified saturated conductivity for the tile is given by:

$K_{s}^{\prime \prime}(z)=K_{s}^{\prime} \cdot \Pi_{v=1}^{13} K_{v}(z)^{f_{v}}$

Where $K_{s}^{\prime}$ is the conductivity taking into account the effect of soil depth (see Sect. 2.1.2), $f_{v}$ is the fraction of vegetation type $v$ on the tile. It is computed as the ratio between 


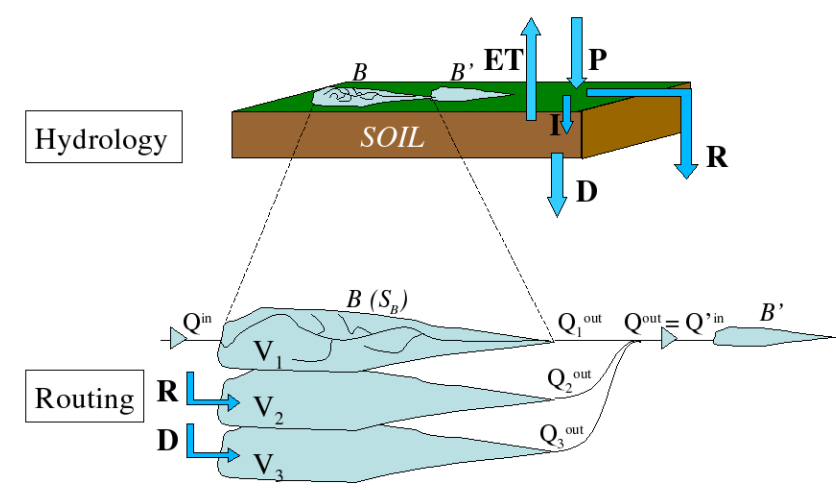

Fig. 1. ORCHIDEE river routing scheme. The hydrology module computes the partitioning of precipitation (P) into infiltration (I) and surface runoff (R) and then into evapotranspitration (ET) and subsurface runoff (D) for each grid box. In the routing module, Each grid box is divided into successive basins $\left(B, B^{\prime}, \ldots\right)$ defined by their surface area $\left(S_{B}\right)$. Each basin includes 3 reservoirs $\left(V_{i}, i=1,2,3\right)$. The river reservoir $\left(V_{1}\right)$ receives flow from head waters of the river $\left(Q^{i n}\right)$. The surface and subsurface runoff reservoirs $\left(V_{2}\right.$ and $\left.V_{3}\right)$ receive surface and subsurface runoff fluxes from the hydrological module. The water flows out of each reservoir $\left(Q_{i}^{\text {out }}, i=1,2,3\right)$ to the next reservoir $\left(Q_{i n}^{\prime}\right)$.

the surface covered by the vegetation type and the surface covered.by the corresponding vegetation ensemble. This formula allows to increase exponentially the saturated conductivity for $z<\frac{1}{c_{v}}$ for each vegetation type $v$. Here the parameterization was calibrated in order to obtain a reasonable evapotranspiration variability in Hapex-Sahel simulations.

\subsection{Routing module}

The routing module is based on Hagemann et al. (1998) and Miller et al. (1994). Surface, subsurface runoff, and river fluxes are routed through three different reservoirs in each basin of each grid box (see reservoirs $V_{i}, i=1,2,3$ for basins $B, B^{\prime}, \ldots$ in Fig. 1).

Each reservoir has a different time constant which only depends on the mean slope of the river and on three constants fixed globally (one per reservoir type). The basin map is based on STN-30p (Fekete et al., 2000), at $0.5^{\circ} \times 0.5^{\circ}$. This simulates horizontal water movements in the large river basins and allows to compute river discharges. This routing scheme is described more thoroughly in Ngo-Duc et al. (2005, 2007) and is shown in Fig. 1.

\subsubsection{Floodplains}

A floodplain module is included in this version of ORCHIDEE to deal with swamps and floodplains such as the ones observed in the Niger Inner Delta or in the Congo basin. Parameters have been fixed through validations against satellite retrievals of climatological floodplain heights (Gennero

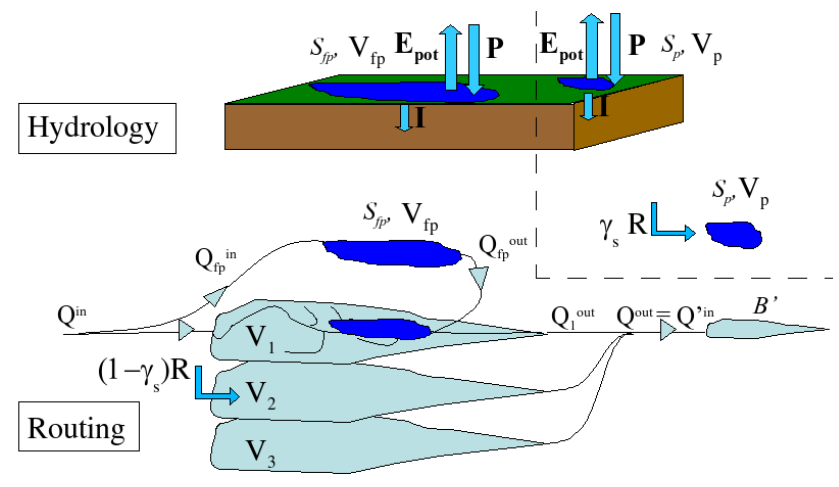

Fig. 2. ORCHIDEE routing scheme with floodplain and pond modules. Optional features are in the dashed boxes. In the hydrology module, the floodplain and the pond reservoirs $\left(V_{f p}, V_{p}\right)$ are characterized by their surface areas $\left(S_{f p}, S_{p}\right)$ over which they receive precipitation $(\mathrm{P})$, they evaporate at the potentiel rate $\left(E_{\mathrm{pot}}\right)$, and they infiltrate into the soil (I). In the routing module, the floodplain reservoir receives flow from head waters of the river $\left(Q_{i n}\right)$ and flows back $\left(Q_{f p}\right)$ into the river reservoir $\left(V_{1}\right)$. The ponds receive a fraction $\gamma_{s}$ of the surface runoff $(\mathrm{R})$ whereas the surface runoff reservoir only receives the fraction $1-\gamma_{s}$. See Fig. 1 for more details.

et al., 2006) and flooded areas (Prigent et al., 2007, 2001) in the Niger Inner Delta for the period 1993-2000.

The maximum area for floodplains per basin $S_{\max }$ is given by the aggregation of fields "Reservoir","Freshwater marsh, Floodplains" and "Pan, Brackish, Saline wetlands" from the Global Lakes and Wetlands Database -GLWD- (Lehner and Doll, 2004). In case $S_{\max }>0, Q$ from the preceding basin flows into the floodplain reservoir instead of the river reservoir.

The floodplain reservoir (see Fig. 2) is characterised by its volume $V_{f p}$. In order to compute the floodplain area $S_{f p}$, a hypothesis is made about the shape of the bottom of the floodplain, in order to link the height of the floodplain $h_{f p}$ to its volume $V_{f p}$ and its area $S_{f p}$ in case $S_{f p}<S_{\max }$ :

$S_{f p}=\min \left(S_{\max }, S_{B}\left(\frac{h_{f p}}{h_{0}}\right)^{\beta}\right)$

where $S_{B}$ is the total basin area, $h_{0}=2 m$ is a constant. For floodplains, $\beta=2$ indicating a convex bottom, and a floodplain that expands more quickly as it rises. Integrating $S_{f p}$ over $h$ would provide $S_{f p}$ as a function of $V_{f p}$.

Over the area $S_{f p}$ the evaporation from the floodplain is at the potential level and the rainfall directly fills the floodplain reservoir. Optionally, water from the floodplain can be reinfiltrated into the soil at an infiltration rate that equals hydraulic conductivity of the first $2 \mathrm{~cm}$ of the soil $\left(K_{2 \mathrm{~cm}}\right)$. The impact of reinfiltration in the floodplain is tested in Sect. 4. Finally, the floodplain flows into the river reservoir with a time constant $\tau_{f p} \cdot \frac{S_{f p}}{S_{B}}$, which tends to zero when the floodplain is empty and to $\tau_{f p}$ when the floodplain is spread out over the whole basin. 


\subsubsection{Ponds}

An optional pond module is added in order to provide a firstorder simulation for small ponds that reevaporate and reinfiltrate surface runoff over flat areas, such as the ones documented in the Niamey region (Peugeot et al., 2003; Cappelaere et al., 2003). Parameters have been fixed to have pond areas of the same order as the ones given by the "temporary wetlands" field in GLWD (Lehner and Doll, 2004). The principle of this module is very similar to the floodplains' one. When the module is activated, reinfiltration is not put directly into the soil column (see Eq. 1). Instead, the reinfiltrated fraction $\overline{\gamma_{s}}$ goes into a pond reservoir (volume $V_{p}$ ). The relationship between pond area and height is the same as for floodplains (see Eq. 5), but for $\beta=0.5$ (concave bottom). Ponds reinfiltrate into the soil at an infiltration rate that equals hydraulic conductivity of the first $2 \mathrm{~cm}$ of the soil ( $K_{2 \mathrm{~cm}}$, same as for the floodplains).

\section{Impacts of soil infiltration on evapotranspiration}

\subsection{Data and methodology}

The forcing used in this section is the baseline forcing B0 from GSWP2 - Global Soil Wetness Project, Phase II (Dirmeyer et al., 2002) - covering 1986-1995 globally at the $1^{\circ} \times 1^{\circ}$ scale. Outputs from the 15 GSWP2 models and from the new version of ORCHIDEE are used. Each model ran 10 years (1986-1995) of simulation after a free number of years of spin-up on 1983 and 3 consecutive years of spin-up (19831985). The whole forcing (1983-1995) has a $3 \mathrm{~h}$ timestep and is based on NCEP/DOE (Kanamitsu et al., 2002), as part of the ISLSCPII initiative. Participating models are presented in Table 3. The version of ORCHIDEE participating in GSWP2 (de Rosnay and Polcher, 1998) is older than the one described in Sect. 2 and used in the next subsection. The older version is not analysed individually in this article and only appears through the GSWP2 multi-model analysis.

Our analysis will be conducted over the land surface bounded by the latitudes $5^{\circ} \mathrm{S}$ and $20^{\circ} \mathrm{N}$, and by the longitude $20^{\circ} \mathrm{W}$ and $30^{\circ} \mathrm{E}$. This area is divided into 4 regions for which the sensitivity to infiltration processes is separately analysed: equatorial $\left(5^{\circ} \mathrm{S}-5^{\circ} \mathrm{N}\right)$, guinean $\left(5^{\circ} \mathrm{N}-\right.$ $\left.10^{\circ} \mathrm{N}\right)$, soudano-sahelian $\left(10^{\circ} \mathrm{N}-15^{\circ} \mathrm{N}\right)$ and saharo-sahelian $\left(15^{\circ} \mathrm{N}-20^{\circ} \mathrm{N}\right)$. These regions correspond to specific geographic characteristics: the equatorial region is mainly covered by rain forest, the guinean region is a transition region composed of humid mountains and of dry plains, the soudano-sahelian region is a semi-arid one with a strong seasonality of precipitation and vegetation. Finally, the saharosahelian region is on the edge of the desert.

In Sect. 3.2, the hydrological balance of ORCHIDEE is presented and compared to the GSWP2 multi-model average and to the spread between GSWP2 models (indicated by the inter-model standard deviation around the average). This is used to give a reference for the uncertainy in simulating the West African hydrological balance before presenting the sensitivity experiments in Sect. 3.3.

\subsection{Hydrological balance in ORCHIDEE simulations}

ORCHIDEE outputs for the control simulation (CTL) are compared to GSWP2 outputs in Fig. 3.

The region where ORCHIDEE differs the most from the GSWP2 multi-model mean is the equatorial region $\left(5^{\circ} \mathrm{S}-\right.$ $5^{\circ} \mathrm{N}$ ). It is the only one where the difference between ORCHIDEE and the multi-model partitionings of precipitation into ET and total runoff (surface and subsurface runoff) exceeds one standard deviation of the model outputs (shaded area). ET from ORCHIDEE is far less than the ET estimated with the other models, due to a much lower average transpiration which leads to high subsurface runoff values. The main parameterizations impacting the transpiration without impacting surface runoff are the change of infiltration capacity with soil depth and the canopy structural resistance (see Table 1). This structural resistance represents the impact of the canopy structure on local turbulence and therefore on the efficiency of vegetation-atmosphere transfer (in s.m ${ }^{-1}$ ). It provides the link between potential evaporation above the vegetation and maximum evapotranspiration at the leaf level.

In the guinean region $\left(5^{\circ} \mathrm{N}-10^{\circ} \mathrm{N}\right)$, the main difference is in the bare soil evaporation, which is much lower for ORCHIDEE. These values are partly compensated by higher transpiration, but overall ET is lower. The main parameterization in ORCHIDEE determining bare soil evaporation without changing the rest of the processes infiltration and evapotranspiration processes is the Monsi and Saeki (1953) law that determines bare soil evaporation under vegetation. The LAI map used has also a significant role in determining the partitioning between bare soil evaporation - favoured by low LAI - and transpiration - favoured by high LAI.

In the soudano-sahelian region $\left(10^{\circ} \mathrm{N}-15^{\circ} \mathrm{N}\right)$, ORCHIDEE simulates a zonal average of each kind of ET close to the multi-model mean. Finally, ORCHIDEE generally tends to produce more subsurface runoff and less surface runoff than the multi-model mean. Therefore, the partitioning between surface runoff and infiltration might be a significant source of uncertainty in the soudano-sahelian region, even if ET is of the same order. This partitioning between surface runoff and infiltration is currently mainly impacted by the parameterization of flat areas.

The differences between ORCHIDEE and the GSWP2 multi-model mean does not imply that ORCHIDEE is wrong but they point out regions where the land-surface processes are differently represented or calibrated in the different models. 
Table 3. Description of GSWP2 models. The time step is given in hours (h) or minutes (min). Two models have a different time step for energy balance (E) and soil hydrology (S). The structure indicates the number of layers for hydrology $(\mathrm{H})$ and for temperature (T). Parameters for soil (S) come either from GSWP-2 (Sg) or from the model default configuration (Sd). For vegetation (V), two datasets were made available: IGBP (Vi) and $\mathrm{SiB}(\mathrm{Vs})$, and some models used default one (Vd). Only one model includes a dynamic vegetation ( $\left.\mathrm{V}^{*}\right)$. More details are given in Dirmeyer et al. (2006).

\begin{tabular}{llllll}
\hline Name & Institute & Time step & Structure & Parameters & Reference \\
\hline BucketIIS & U. Tokyo & $3 \mathrm{~h}$ & $1 \mathrm{H} 1 \mathrm{~T}$ & $\mathrm{n} / \mathrm{a}$ & Manabe (1969) \\
CLM2-TOP & U. Texas & $1 \mathrm{hE}$ & $10 \mathrm{H} 10 \mathrm{~T}$ & $\mathrm{Sd} \mathrm{Vd}$ & Bonan et al. (2002) \\
& & $5 \mathrm{minS}$ & & & \\
Sland & U. Maryland & $20 \mathrm{~min}$ & $1 \mathrm{H} 2 \mathrm{~T}$ & $\mathrm{Sd} \mathrm{V}$ & Zeng et al. (2005) \\
HY-SSiB & GSFC & $30 \mathrm{~min}$ & $3 \mathrm{H} 2 \mathrm{~T}$ & $\mathrm{Sd} \mathrm{Vs}$ & Mocko and Sud (2001) \\
ISBA & CNRM & $5 \mathrm{~min}$ & $3 \mathrm{H} 2 \mathrm{~T}$ & $\mathrm{Sd} \mathrm{Vi}$ & Etchevers et al. (2001) \\
LaD & GFDL & $30 \mathrm{~min}$ & $1 \mathrm{H} 18 \mathrm{~T}$ & $\mathrm{Sd} \mathrm{Vs}$ & Milly and Shmakin (2002) \\
MOSES2 & Met Office & $30 \mathrm{~min}$ & $4 \mathrm{H} 4 \mathrm{~T}$ & $\mathrm{Sd} \mathrm{Vd}$ & Essery et al. (2003) \\
Mosaic & NASA & $30 \mathrm{~min}$ & $3 \mathrm{H} 2 \mathrm{~T}$ & $\mathrm{Sg} \mathrm{Vs}$ & Koster and Suarez (1992) \\
NOAH & NOAA & $15 \mathrm{~min}$ & $4 \mathrm{H} 4 \mathrm{~T}$ & $\mathrm{Sg} \mathrm{Vd}$ & Ek et al. (2003) \\
NSIPP-C. & NASA & $20 \mathrm{~min}$ & $3 \mathrm{H} 6 \mathrm{~T}$ & $\mathrm{Sg} \mathrm{Vs}$ & Koster et al. (2000) \\
ORCHIDEE & IPSL & $30 \mathrm{~min}$ & $2 \mathrm{H} 7 \mathrm{~T}$ & $\mathrm{Sd} \mathrm{Vd}$ & Krinner et al. (2005) \\
SiBUC & Kyoto U. & $1 \mathrm{~h}$ & $3 \mathrm{H} 2 \mathrm{~T}$ & $\mathrm{Sg} \mathrm{Vd}$ & online \\
SSiBCOLA & COLA & $30 \mathrm{~min}$ & $6 \mathrm{H} 6 \mathrm{~T}$ & $\mathrm{Sg} \mathrm{Vs}$ & Dirmeyer and Zeng (1999) \\
SWAP & IWP & $3 \mathrm{~h}$ & $2 \mathrm{H} 1 \mathrm{~T}$ & $\mathrm{Sg} \mathrm{Vi}$ & Gusev and Nasonova (2003) \\
VISA & U. Texas & $3 \mathrm{hE}$ & $10 \mathrm{H} 10 \mathrm{~T}$ & $\mathrm{Sd} \mathrm{Vd}$ & Yang and Niu (2003) \\
& & $5 \mathrm{minS}$ & & & \\
\hline
\end{tabular}

(a)

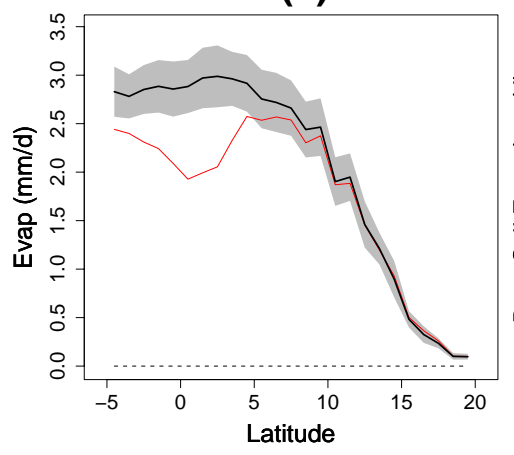

(d)

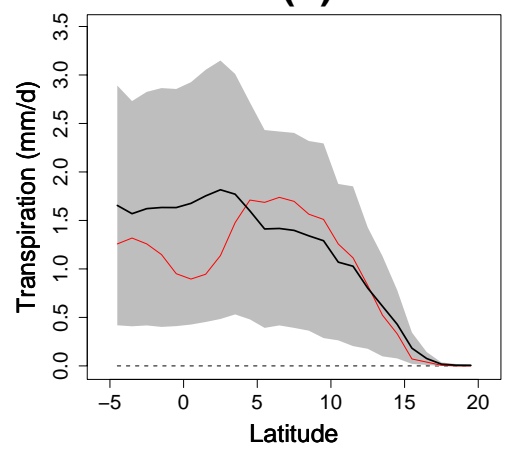

(b)

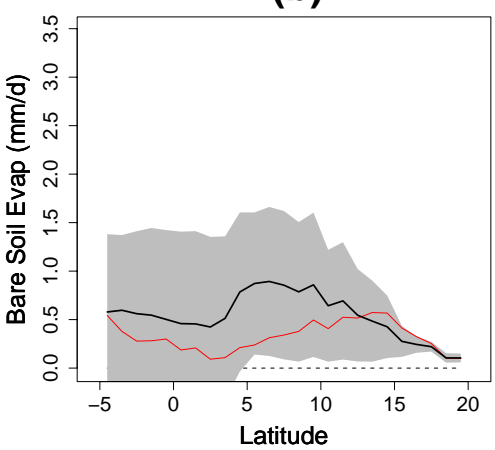

(e)

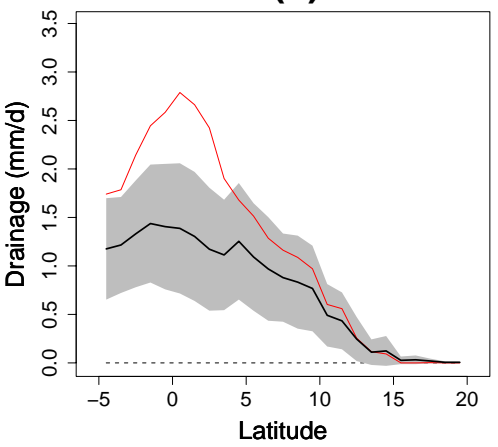

(c)

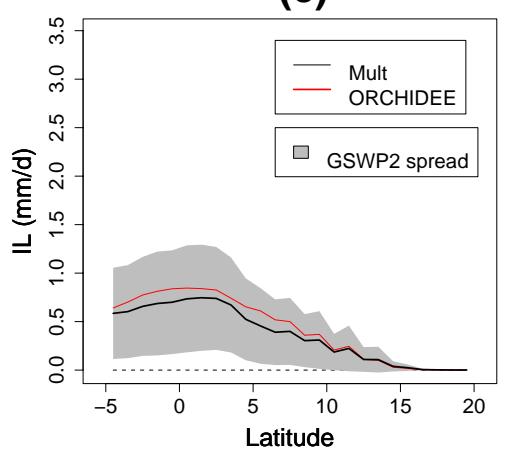

(f)

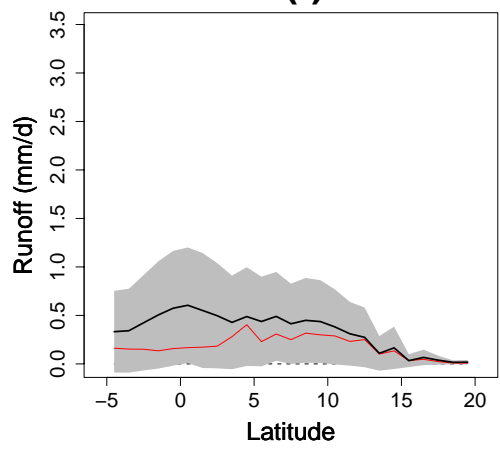

Fig. 3. Zonal (20 W-30 E) and temporal (1986-1995) averages of (a) evapotranspiration, (b) bare soil evaporation, (c) interception loss, (d) transpiration, (e) subsurface runoff and (f) surface runoff given by GSWP2 multi-model mean (in black) and by ORCHIDEE (in red). The shaded area corresponds to multi-model mean plus or minus the standard deviation of GSWP2 model outputs. 
Table 4. Summary of sensitivity tests performed with ORCHIDEE.

\begin{tabular}{ll}
\hline Name & Principle \\
\hline BS & Bare soil evaporation not allowed under vegetation \\
I1 & Reinfiltration not allowed in flat areas \\
I2 & Infiltration not increased by roots \\
I3 & Constant infiltration with depth \\
CR & Canopy structural resistance doubled \\
\hline
\end{tabular}

\subsection{Sensitivity experiments to soil infiltration}

In order to explore more precisely the role of the different infiltration processes, some sensitivity experiments to the three infiltration parameterizations of this new version of ORCHIDEE are performed in this sub-section, respectively called I1, I2 and I3. Two additional experiments are done to compare the impact of infiltration parameterizations to the parameterizations that play a dominant role in evapotranspiration processes. The first experiment is on the role of bare soil evaporation (BS) and the second on the role of the canopy structural resistance (CR) which is a main limiting factor for interception loss and transpiration at the leaf level. Table 4 presents the five sensitivity experiments. Each sensitivity experiment consists of a GSWP2 baseline simulation (forced by baseline forcing B0 from 1986 to 1995).

The ET anomaly between the control experiment (CTL) and each sensitivity experiment is computed for the 4 different regions of interest (equatorial, guinean, soudano-sahelian and saharo-sahelian: see Sect. 3.1) and results are presented in Fig. 4.

Sensitivity to bare soil evaporation (CTL-BS) is higher in the soudano-sahelian region than in other regions. This is due to the fact that LAI is much more variable there and therefore the relationship between LAI and bare soil evaporation (Monsi and Saeki, 1953) is crucial. Impact of this change on the guinean region is much less important.

Reinfiltration for flat areas (CTL-I1) also has a dominant impact on the soudano-sahelian region, but it plays an important role in the guinean region too. Indeed, there is a large guinean zone with low orography between $5^{\circ} \mathrm{W}$ and $5^{\circ} \mathrm{E}$ where the parameterization of reinfiltration significantly changes the partitioning between surface runoff and infiltration.

The impact of roots on infiltration (CTL-I2) is slightly more important in the guinean region than in the soudanosahelian one. The impact of depth (CTL-I3) is even more important in the guinean region. These two features may be linked to the presence of vegetation with longer roots in the guinean region. This will be discussed in Sect. 5 .

Finally, the above-mentioned parameterizations have very little impact on the equatorial region, in which ET is mainly sensitive to the canopy structural resistance (CTL-CR).

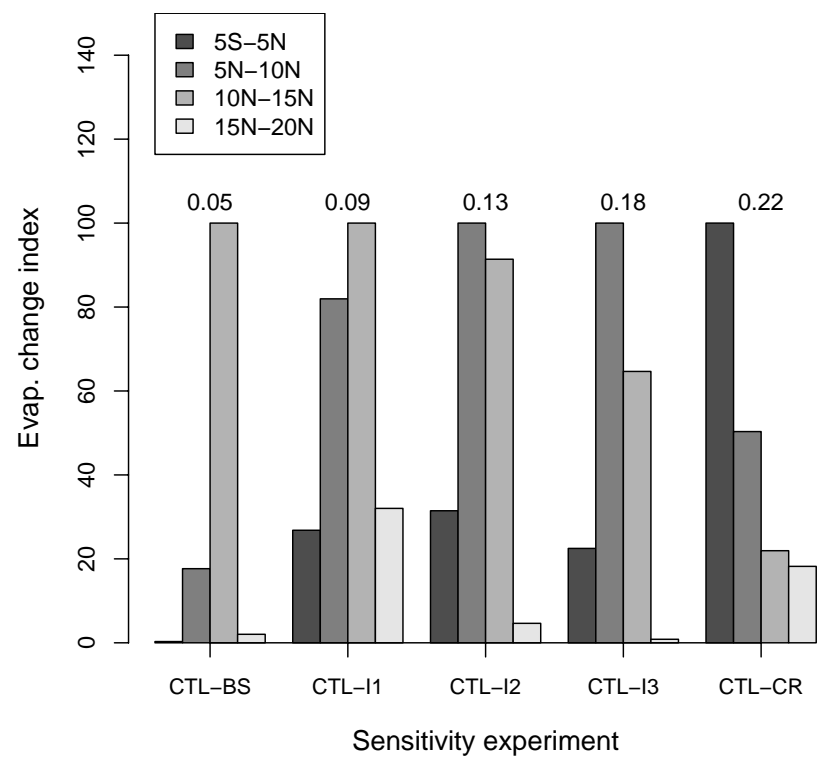

Fig. 4. Relative mean evapotranspiration anomaly (1986-1995) between the control simulation and each sensitivity experiment in 4 different regions defined by their latitude boundaries (zonal mean between $20^{\circ} \mathrm{W}-30^{\circ} \mathrm{E}$ ). The evapotranspiration change index gives the ratio $(\%)$ between the evapotranspiration anomaly for the indicated region and the maximum evapotranspiration anomaly among the 4 regions. The maximum evapotranspiration anomaly value is indicated above each bar group.

\section{Impacts of river reinfiltration on discharges}

\subsection{Data and Methodology}

In this section, simulations of ORCHIDEE are performed with the river scheme and the floodplain module activated. The pond module is also used for the sensitivity experiment in Sect. 4.3. Forcing data is NCC (Ngo-Duc et al., 2005), which is based on NCEP reanalysis (Kalnay et al., 1996), corrected by CRU data (New et al., 2000). For each simulated couple of year $\mathrm{Y}-\mathrm{Y}+1,8$ years of spin-up are performed for $Y-3$, and then the model is run chronologically from Y-3 to $\mathrm{Y}+1$.

Outputs are validated against African river discharges from the UCAR (University Corporation for Atmospheric Research) database (http://dss.ucar.edu/datasets/ds552.1/). In order to get a more robust idea of ORCHIDEE performance, rivers from the whole African continent are used here. The period used for validation consists of two sets of years: 1954-1955 and 1971-1972. These two sets are chosen because they are the years when most river discharges are available without missing values among the African stations. Moreover, 1954-1955 is during a humid phase and 19711972 is the beginning of the drought that lasted until the beginning of the 90s. Therefore the validation of ORCHIDEE on both periods gives an idea of its robustness. Multi-year 
Table 5. Stations from the UCAR database selected for ORCHIDEE validation. *Area is given in $10^{3} \mathrm{~km}^{2}$

\begin{tabular}{llccc}
\hline Name & Station & River & Lon-Lat & Area* \\
\hline \multicolumn{5}{c}{ West-African catchments } \\
KoN & Koulikoro & Niger & $7.5^{\circ} \mathrm{W}-12.9^{\circ} \mathrm{N}$ & 120 \\
$\mathrm{MaN}$ & Malanville & Niger & $3.4^{\circ} \mathrm{E}-11.9^{\circ} \mathrm{N}$ & 1000 \\
$\mathrm{BaV}$ & Bamboi & B.Volta & $2.0^{\circ} \mathrm{W}-8.2^{\circ} \mathrm{N}$ & 134 \\
$\mathrm{EdS}$ & Edea & Sanaga & $10.1^{\circ} \mathrm{E}-3.8^{\circ} \mathrm{N}$ & 132 \\
\multicolumn{5}{c}{} \\
KiC & Kinshasa & Congo & $15.3^{\circ} \mathrm{E}-4.3^{\circ} \mathrm{S}$ & 3475 \\
$\mathrm{DoN}$ & Dongola & Nile & $30.5^{\circ} \mathrm{E}-19.2^{\circ} \mathrm{N}$ & 2694 \\
$\mathrm{ChS}$ & Chiromo & Shire & $35.1^{\circ} \mathrm{E}-16.6^{\circ} \mathrm{S}$ & 150 \\
$\mathrm{LuJ}$ & Luug & Juba & $42.3^{\circ} \mathrm{E}-3.6^{\circ} \mathrm{N}$ & 179 \\
\hline
\end{tabular}

means of ORCHIDEE river flow outputs are compared to observations. The validation chosen here only tests the annual averages of river discharges and does not allow for the identification of errors in the annual cycle.

In the UCAR database, river discharge stations are selected according to 4 criteria:

- The size of the catchment. ORCHIDEE's basin map scale is $0.5^{\circ} \times 0.5^{\circ}$, which may lead to significant errors in the catchment area for small basins or for stations that are close to a confluence. Therefore stations are discarded if their catchment area is below $100000 \mathrm{~km}^{2}$ or if ORCHIDEE's error in the catchment area exceeds $20 \%$. However, the small size of the catchments will still be a source of uncertainty even if these threshold are respected, because modeled and observed catchment do not perfectly match and high precipitation areas may be misplaced.

- Position on the river. If two stations are on the same river, and the behaviour of ORCHIDEE is similar for both of them, only the downstream one is shown. For example on the Niger basin, only Malanville and Koulikoro are kept.

- Floodplains surrounding the station. If the station is surrounded by floodplains (less than $100 \mathrm{~km}$ ), the corresponding output from ORCHIDEE is the discharge after a large simulated floodplain. In reality, the station might be between two floodplains or before a floodplain, and therefore ORCHIDEE simulations may not be consistent with the observations. All the stations on the Chari are discarded by this criterion.

- Availability of data over the 4 given years (1954-1955 and 1971-1972).

Only 8 African catchments correspond to the above criteria and are described in Table 5.
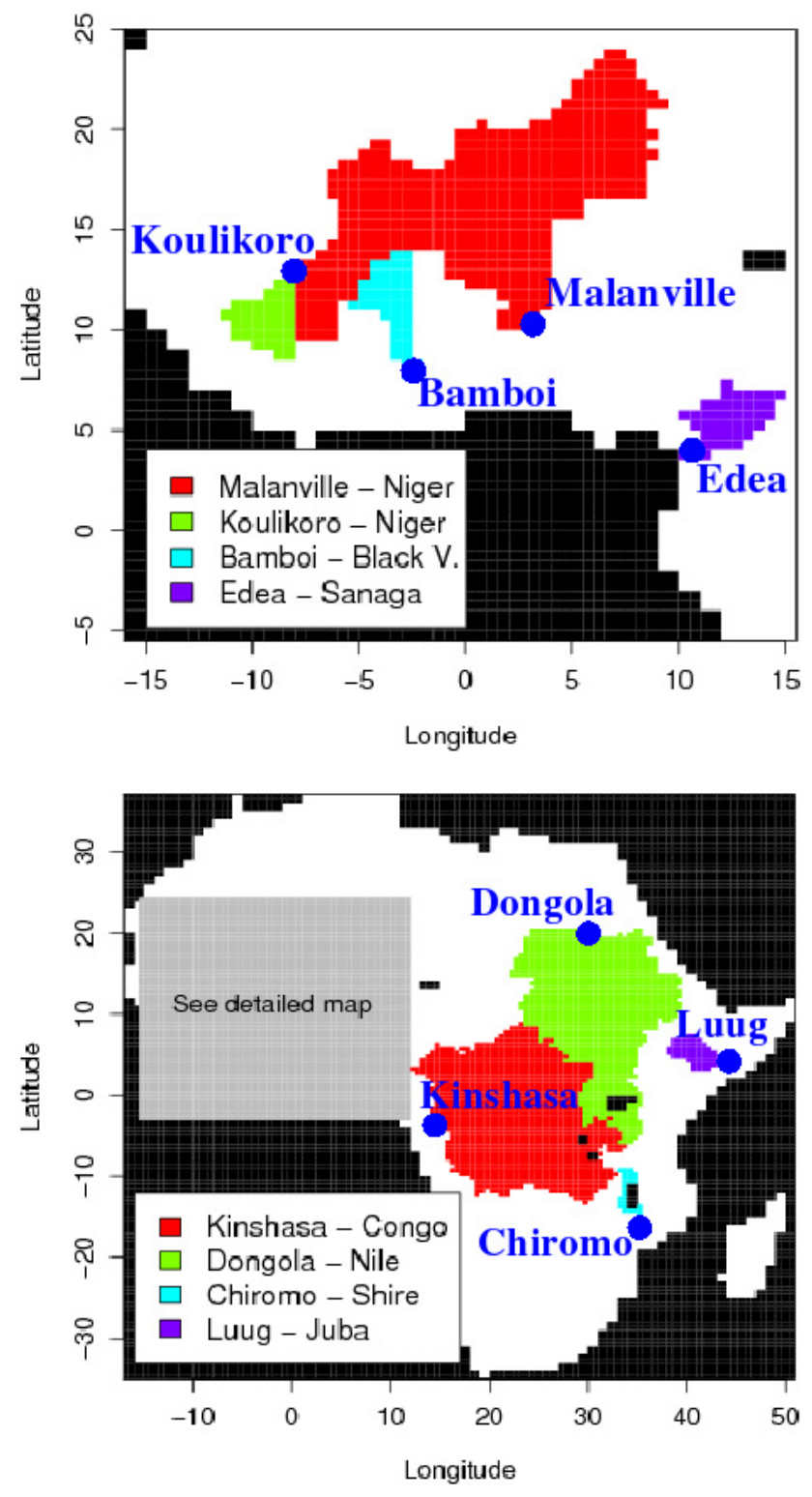

Fig. 5. Maps of the catchments simulated by ORCHIDEE for West Africa (left) and Central and East Africa (right)

Two maps of the catchments simulated by ORCHIDEE are given in Fig. 5.

In the figures presented in the next sections, the mean difference over the 4 years between ORCHIDEE's results and the discharge observations are presented for each catchment in percent of the observed discharge. This mean difference will be called 'error' thereafter. Positive percentages indicate overestimations by ORCHIDEE. Next the sensitivity to forcing, parameters and parameterizations is analysed. For each test, the change in discharge that would come from the change of forcing, paramters or parameterization is computed. If the change tends to compensate for the error, a "sensitivity bar" is drawn in the same direction as the error bar. If 
the 'sensitivity bar' is opposite, it means that the change of forcing, parameter or parameterization tends to worsen the control result.

Before conducting the sensitivity tests to infiltration processes in floodplains and ponds, an analysis of the uncertainty linked to the LSM inputs is performed. The aim is to provide a reference to compare with the sensitivity tests on river infiltration processes. The role of three LSM inputs is tested here: precipitation, soil and vegetation.

To estimate the sensitivity to the precipitation forcing, it is not possible to perform a direct sensitivity experiment because only one forcing was available for two pairs of years (1954-1955 and 1971-1972). ORCHIDEE control simulations are forced by NCC, which means that monthly precipitation values come from CRU (NCEP values are corrected by CRU on a monthly basis). A precipitation dataset from IRD (Institut de Recherche pour le Développement) is used to compare with CRU. This dataset consists of daily values of precipitation from 1968 to 1992 , interpolated on a $1^{\circ} \times 1^{\circ}$ grid over West Africa (Le Barbé et al., 2002). For each West African basin (Table 5 and Fig. 5), the average anomaly between IRD and CRU datasets over each basin and over the 25 years is computed. Then an analysis of interannual variability of precipitation and total runoff is done in a simulation of ORCHIDEE forced by NCC from 1951 to 2000 (d'Orgeval and Polcher, 2008). The ratio $R_{\sigma}=\frac{\sigma_{R}}{\sigma_{p}}$ between interannual standard deviation of total runoff and precipitation is computed for each basin. This gives a first estimate of the impact of a precipitation anomaly on total runoff anomaly in ORCHIDEE. The values for the four basins are between 0.9 and 0.95 and precipitation anomaly for each basin is multiplied by $R_{\sigma}$ in order to give an estimation of total runoff anomaly due to the change of precipitation dataset. Finally, total runoff is integrated over the basin area to give the discharge anomaly.

This discharge anomaly is a first guess of ORCHIDEE's error due to the precipitation forcing. It is computed over a large period (1968-1992) to be more robust and coherent with the IRD dataset, but it has to be noted that the uncertainty value is not computed for the same years as ORCHIDEE's error. Moreover, the uncertainty is given by the biases in the multi-year average value of precipitation integrated over each basin. The real uncertainty might be higher because total runoff anomalies do not respond linearly to precipitation anomalies. Therefore, there might be precipitation anomalies that compensate for each other in the multi-year average or in the integration over the basin, but which lead to total runoff anomalies that do not compensate. However, as the uncertainty computation can not be significantly improved with currently available data, the given value should be used as a first estimation.

For soil types, the control simulation is performed with a dataset by Reynolds et al. (1999). The sensitivity experiment is done by changing the soil map back to the Zobler (1986) map which used to be the control one for ORCHIDEE (de Rosnay and Polcher, 1998). Howver, this sensitivity test is somewhat limited because both maps come from the same original FAO database (Food and Agriculture Organization, 1978), the difference being in additional datasets used, and in the algorithm to convert the original database into FAO soiltypes. For vegetation types, the default map is derived from the IGBP map with the Olson classification (de Rosnay and Polcher, 1998). The sensitivity experiment consists in changing the map to a map derived from Sterling and Ducharne (2006).

\subsection{Role of LSM inputs}

Results are presented in Fig. 6. Two basins - Malanville and Dongola catchments - have a discharge error beyond $90 \%$ of the observed discharge, four - Koulikoro, Bamboi, Edea, Chiromo - give an error between $30-60 \%$ and two below 25\% - Kinshasa and Luug. ORCHIDEE overestimates the river flows for 6 of them and underestimates 2 of them Bamboi and Chiromo. Results are fairly similar in both sets of years apart from the discharges at Malanville. This means that the interannual variability of discharge at this station is not well represented, which may be due to the parameterization of floodplains (d'Orgeval and Polcher, 2008). Moreover, no link was found between the main vegetation, soil, orography or other geographical parameters and the discharge error among the different basins, which means that ORCHIDEE does not have any systematic bias depending on one of these simple parameters in this region.

Precipitation uncertainty is shown in Fig. 6 to be of major importance. It is even larger than the model error at Malanville, it represents half of it in Koulikoro and Edea catchments, but only $2.5 \%$ of the error at Bamboi. For the East African basins, IRD data is not available and the uncertainty could not be evaluated.

Uncertainty linked to the soil map seems to be significant only in Luug, where it is close to half of the observed discharge. In the other catchments, it is not a first-order uncertainty: the discharge anomaly due to the change of soil map is below $10 \%$ of the observed discharge. A closer analysis shows that Luug is the only basin where a significant part of the soil is classified as medium in one map and as fine in the other (not shown).

Finally, the impact of vegetation change is around 50\% of the observed discharge for Kinshasa and Malanville. It is also close to $20 \%$ for Luug, and may account for the discharge error. Uncertainty linked to vegetation is the highest for the large basins where bare soil is not dominant (Kinshasa and Malanville, but not Dongola). An analysis of both maps shows that in semi-arid and intermediate basins the IGBP map has more $\mathrm{C} 3$ grass and tropical forests where the Sterling and Ducharne (2006) map has more C4 grass. In equatorial basins, the IGBP map has more $\mathrm{C} 3$ grass and bare soil where the Sterling and Ducharne (2006) map has more equatorial forests. This uncertainty may be linked to the 


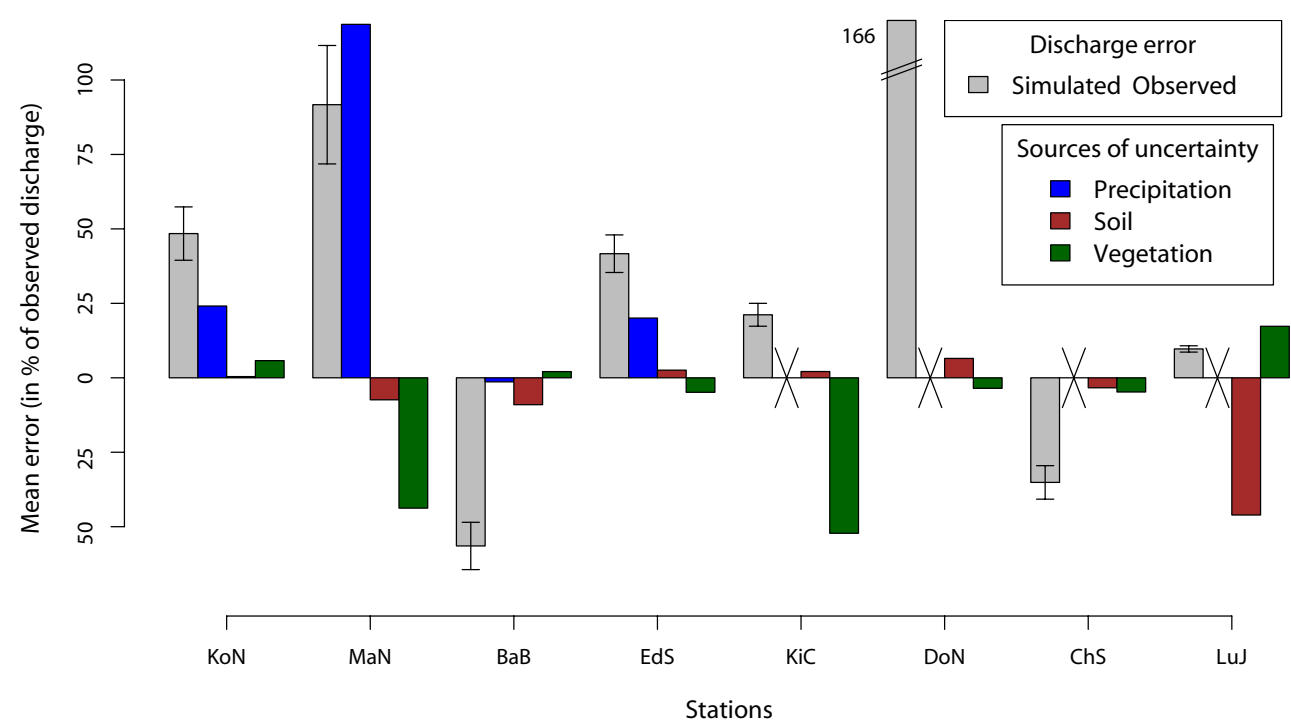

Fig. 6. Errors and sources of uncertainty in ORCHIDEE simulations for 8 river catchments (see Table 5), in percent of observed discharge for 1954-1955 and 1971-1972. The end points of the black T-bars indicate individual values of discharge errors for 1954-1955 and 1971-1972. Crosses indicate that no precipitation data was available to evaluate uncertainty coming from the precipitation input.

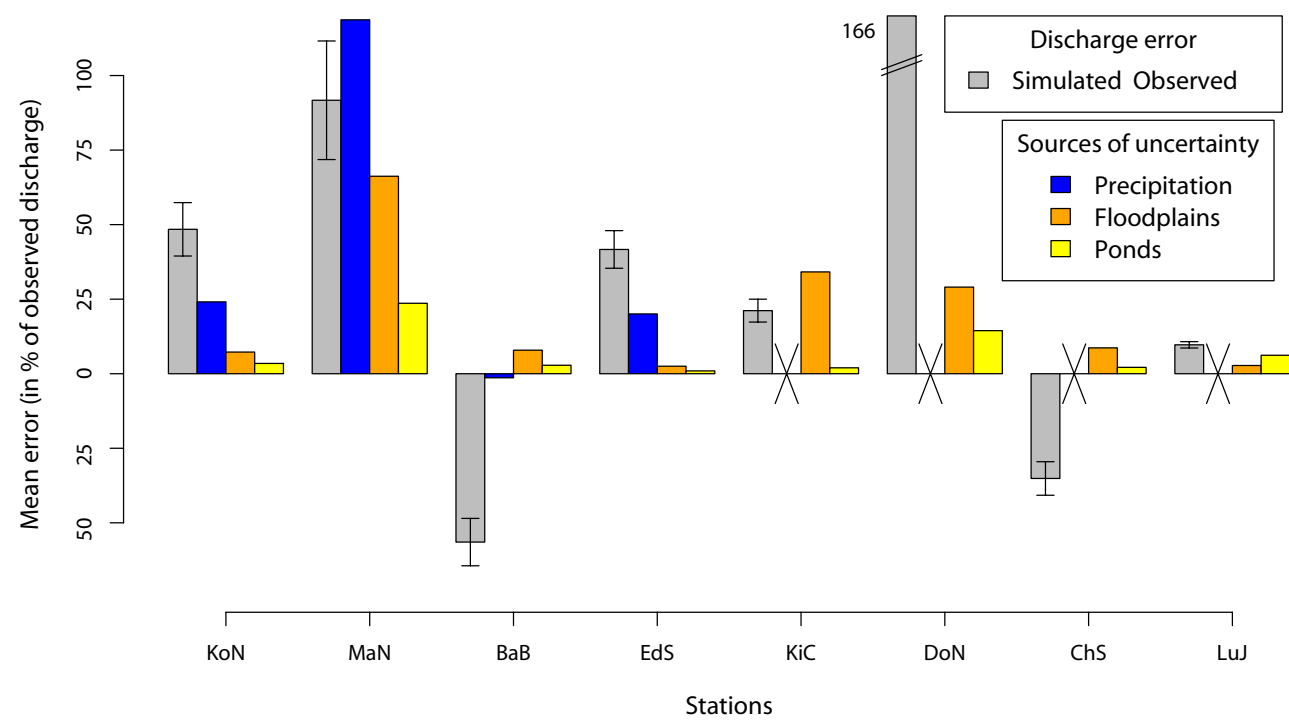

Fig. 7. Errors and sources of uncertainty in ORCHIDEE simulations for 8 river catchments (see Table 5), in percent of observed discharge. Crosses indicate that no precipitation data was available to evaluate uncertainty coming from the precipitation input.

classification of heterogeneous vegetation grid points (Sterling and Ducharne, 2006).

\subsection{Sensitivity experiment to river reinfiltration}

The aim of this subsection is to present the sensitivity of river discharge simulated by ORCHIDEE to reinfiltration in African river basins. The two sensitivity experiments performed are linked to the parameterizations of floodplains and ponds. The first one consists in allowing the water in floodplains to reinfiltrate into the soil (see Fig. 2 and corresponding description). The second one consists in adding a pond module (see Fig. 2 and corresponding description) to the routing scheme. Results are presented in Fig. 7, where discharge error and precipitation uncertainty are also plotted as a reference.

Reinfiltration in floodplains is a major source of uncertainty in the 3 largest catchments - Malanville, Kinshasa and Dongola -, whereas it is negligible elsewhere. Indeed, maximum floodplain areas $S_{\max }$ for these basins are much higher than for the other ones: they represent more than $35000 \mathrm{~km}^{2}$ 
for each of the three basins, whereas it is less than $2000 \mathrm{~km}^{2}$ for the others. This represents a floodplain fraction of more than $1.5 \%$ of the catchment area for the three large basins. The only other catchment which has a floodplain fraction larger than $1.5 \%$ is Koulikoro, but for a much smaller catchment size. It can be infered that for a same maximum floodplain fraction, the impact is more important in large catchments because the time of residence of water will be longer in the large aggregated floodplains within the larger catchments. So the parameterization of floodplains has a strong impact on the simulated hydrological cycle of the largest basins and the most important factors are the residence time of water and the surface covered, which will help to determine the additional ET. An example of the annual cycle simulated by ORCHIDEE is given for Malanville in Fig. 8. The annual cycle is simulated by three versions of ORCHIDEE: without the floodplain module (this version is not used in the rest of the article), with the floodplain module and with floodplain and reinfiltration process in the floodplain. This highlights the role of floodplain for this particular basin.

Ponds seem to be a much less important component of the basin scale hydrological balances. However, their impact is non-negligible in the three most arid basins - Malanville, Dongola and Luug. The other important factor is the orography of these basins, because the fraction of surface runoff that flows into ponds is directly linked to the average slope in the grid box in our parameterization.

\section{Discussion}

Section 3 has shown that infiltration processes have a variable role depending on the latitude of the region considered in West Africa, which is mainly due to the zonality of precipitation and vegetation. The regions of interest for the infiltration processes clearly are the intermediate regions between the humid and arid ones. In the humid regions such as the equatorial region, the atmospheric demand is the limiting factor, soil moisture being available in sufficient quantity. In the arid regions such as the saharo-sahelian region, the limiting factor is precipitation, almost all of it being evaporated at the surface. Therefore, in these two regions infiltration processes play a marginal role.

In the intermediate regions such as the guinean region and the soudano-sahelian region, both atmospheric demand and precipitation have an impact. Therefore, infiltration processes play an important role in determining the partitioning of precipitation into evapotranspiration and total runoff. The guinean region is mainly influenced by rootzone and deepsoil infiltration processes, whereas the soudano-sahelian region is more sensitive to surface infiltration and evaporation processes. Reasons are linked to the types of climate and vegetation: the guinean region is more humid, there is a lower proportion of bare soil and vegetation has longer roots than in the soudano-sahelian region. On the one hand, the

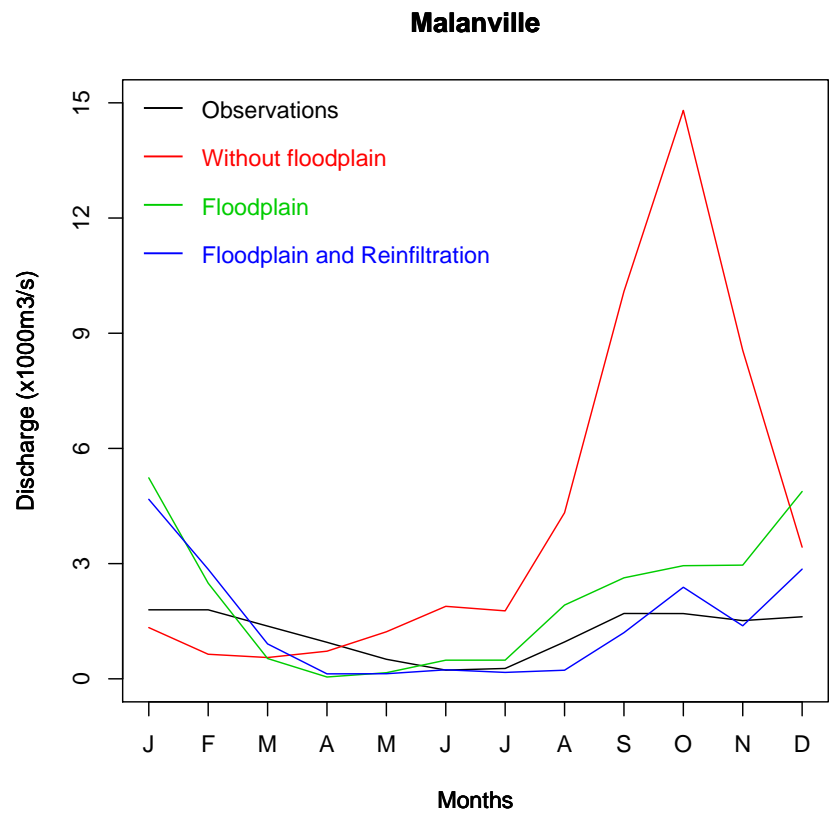

Fig. 8. Mean annual cycle of river discharge at Malanville for the years 1954-1955 and 1971-1972: observed (black), simulated without floodplain module (red), with floodplain module (green) with floodplain and reinfiltration (blue).

low proportion of bare soil naturally decreases the part of bare soil evaporation and reduces the impact of surface infiltration. On the other hand, the longer roots tend to increase infiltration into the rootzone and can extract water from deeper layers in the soil where infiltration is slowed down by the increased compactness. These reasons account for the stronger impact of rootzone and deep-soil infiltration parameterizations in the guinean region.

Schematically, the partitioning of the throughfall (precipitation minus interception loss) between evapotranspiration and total runoff first involves a partitioning between bare soil evaporation, suface runoff and surface infiltration, and then a partitioning between transpiration and subsurface runoff. In the guinean region, the partitioning of precipitation is mainly sensitive to the second partitioning whereas in the soudanosahelian region, the first partitioning also plays a significant role. Indeed, according to the GSWP2 multi-model mean, bare soil evaporation plus surface runoff represents respectively $34 \%$ and $43 \%$ of the throughfall in the guinean region and the soudano-sahelian (transpiration plus subsurface runoff represents respectively $66 \%$ and $57 \%$ in the guinean and soudano-sahelian region). In addition, root extraction in the soudano-sahelian region is more concentrated in the first layers of the soil (not shown), which may be another explaination for the predominance of surface infiltration processes in this region.

In order to compare results from Sect. 3 and from Sect. 4, it is necessary to find a classification for the basins studied 
Table 6. Details on precipitation observations and mean total runoff given in $\mathrm{mm} . \mathrm{d}^{-1}$ over each basin. ${ }^{*} N=$ mean number of raingauges in $10^{3} \mathrm{~km}^{2}, \%_{N>2}=$ percentage of grid boxes where $N>2$, $\bar{P}$ mean precipitation and $\bar{R}$ mean total runoff (surface plus subsurface runoff) in $\mathrm{mm} \cdot \mathrm{d}^{-1}$ averaged over each basin and for the years 1954-1955 and 1971-1972.

\begin{tabular}{lcccc}
\hline Basin & $\bar{P}^{*}$ & $\bar{R}$ & $N^{*}$ & $\%_{N>2}{ }^{*}$ \\
\hline $\mathrm{KoN}$ & 4.0 & 1.2 & 23 & 100 \\
$\mathrm{MaN}$ & 1.0 & 0.07 & 10 & 65 \\
$\mathrm{BaB}$ & 2.5 & 0.15 & 31 & 100 \\
$\mathrm{EdS}$ & 4.6 & 1.3 & 11 & 100 \\
$\mathrm{KiC}$ & 4.0 & 1.0 & 2.7 & 46 \\
$\mathrm{DoN}$ & 1.7 & 0.08 & 6.7 & 85 \\
$\mathrm{ChS}$ & 2.2 & 0.20 & 8 & 100 \\
$\mathrm{LuJ}$ & 1.8 & 0.09 & 2.9 & 95 \\
\hline
\end{tabular}

similar to the classification of the different subregions. Mean precipitation and total runoff are presented for each basin in Table 6. According to these figures, river basins can be classified as follows:

- Semi-humid basins (Edea, Koulikoro, Kinshasa) receive an average precipitation above $4 \mathrm{~mm} \cdot \mathrm{d}^{-1}$ and produce total runoff above $1 \mathrm{~mm} . \mathrm{d}^{-1}$ (river discharge representing $25 \%$ of the precipitation).

- Intermediate basins (Bamboi, Chiromo) receive an average precipitation close to $2.5 \mathrm{~mm} \cdot \mathrm{d}^{-1}$ and produce total runoff close to $0.2 \mathrm{~mm} . \mathrm{d}^{-1}$ (river discharge representing $5-10 \%$ of the precipitation).

- Semi-arid basins (Malanville, Dongola, Luug) receive an average precipitation below $2 \mathrm{~mm} \cdot \mathrm{d}^{-1}$ and produce total runoff below $0.1 \mathrm{~mm} . \mathrm{d}^{-1}$ (river discharge representing $5 \%$ of the precipitation).

No basin is classified as purely humid or arid, because the basins generally extend over different region types and therefore are impacted by infiltration processes in intermediate regions.

In the semi-humid basins, ORCHIDEE overestimates river discharges by $20-50 \%$. However, almost half of the error can be explained by errors in the precipitation forcing. For the Congo basin at Kinshasa, no analysis of the precipitation uncertainty was carried out but the low density of raingauges (mean number of raingauges per grid box and number of grid boxes with more than two raingauges - see Table 6) indicates that the precipitation uncertainty should be very high. The parameterization of reinfiltration in the Congo floodplains can also entirely explain the error. For the two other basins (Koulikoro and Edea), surface infiltration has a negligible impact, which is consistent with the fact that surface infiltration processes are not dominant in semi-humid areas. The overestimated river discharge could be explained there by a canopy structural resistance that is too high, resulting in a decrease in transpiration. Increasing transpiration in the humid regions by reducing the canopy structural resistance would lead to reduced discharge error. It would also cause ORCHIDEE to yield results which are closer to those obtained with the other LSMs in GSWP2 (see Fig. 3). However, the sensitivity to the vegetation map is high for example for the river discharge at Kinshasa. So, the vegetation map may be responsible for part of the error.

In the intermediate basins, ORCHIDEE underestimates river discharges by $30-60 \%$ and the sensitivity experiments performed do not indicate that the forcings or the river reinfiltrations explain this error. It is possible that the parameterizations of rootzone and deep-soil infiltration in ORCHIDEE which have been fixed according to Hapex-Sahel observations leads to an overestimated transpiration in the intermediate basins. Interestingly, Fig. 3 also shows that transpiration is higher in ORCHIDEE than in other LSMs for the intermediate regions such as the guinean region. However, there is no observation that leads to question the much lower bare soil evaporation in ORCHIDEE than in other LSMs for this region. As infiltration processes are important in these basins, the soil map might be a significant source of uncertainty. Indeed, uncertainty linked to the soil proved to be small but the sensitivity experiments conducted for this analysis were not sufficient to draw any definitive conclusion because the different soil maps used here are based on the same sources of information (the database from Food and Agriculture Organization (1978)).

In the semi-arid basins and especially in the large ones (Malanville and Dongola), ORCHIDEE overestimates river discharges. However, this overestimation can be explained by the precipitation uncertainty, which is high in Malanville and should also be a first-order uncertainty at Dongola and Luug because the density of raingauges is quite low (see Table 6). Moreover, surface reinfiltration plays an important role in these basins, which is consistent with the role of surface processes in semi-arid regions such as the soudanosahelian region. These reinfiltration processes may also explain a major part of the error in ORCHIDEE simulations, and should be the focus for the large semi-arid basins. Errors in the river discharge might also be explained by water storage and release in the basins at timescales longer than 2 years (the discharge being averaged over two couples of years). These types of storage were shown to have a significant impact at small scale (Peugeot et al., 2003), but their role at large scale does not seem to be of major importance (d'Orgeval and Polcher, 2008).

\section{Conclusions}

In this article, new infiltration parameterizations have been presented and tested at large scale over the West African region. Three parameterizations for soil infiltration aim at 
representing respectively the impact on infiltration of flat areas, roots in the soil and changes in soil compactness with depth. Two modules to simulate river reinfiltration in floodplains and ponds were also introduced. These paramterizations allowed for the identification of sensitivities in the West African hydrological cycle that should not be specific to ORCHIDEE.

First, the sensitivity to soil infiltration parameterization was investigated. It allowed to classify the different impacts of infiltration: Surface infiltration has a stronger impact on the soudano-sahelian region whereas rootzone and deep-soil infiltration have a stronger impact in the guinean region. Next simulations of river discharge were compared to observed river discharge and the sensitivity to the river reinfiltration processes was tested. The results of the simulations led to a classification between semi-humid, intermediate and semi-arid basins. The river discharge simulations in these three basin types are respectively sensitive to the canopy structural resistance, to the rootzone or deep-soil infiltration processes and to the river reinfiltration processes. However, calibration of Land Surface parameterizations over the semi-humid, intermediate and semi-arid basins should take into account the uncertainties associated with the vegetation map, the soil map and the long term storage processes. Moreover, precipitation is a major source of uncertainty for the simulations in almost every basin (to a lesser extent in the small guinean basins).

Therefore, the validation of new parameterizations in any African region through integrative measurements such as river flows faces many challenges because uncertainty linked to the different inputs (e.g. soil, vegetation, precipitation) is high. Improving the observation systems for these different inputs should be the first step for future validation of infiltration processes in West Africa. The importance of uncertainty implies that the model should be recalibrated with care to avoid over-parameterization. Indeed, if parameterizations were changed or new paramterizations added in order to reduce the error to a minimum in the simulations performed, it would not necessarily lead to improved simulations because the model would then be calibrated to compensate errors in the forcing or the inputs. Therefore, the best way to get a robust validation for a LSM consists in comparing each error of the model to a measure of the uncertainty coming from different sources.

The AMMA field experiment has allowed for the instrumentation of small catchments in 3 super-sites (Gourma, Niamey and High-Oueme) which will hopefully enable us to perform the above-mentioned regional validation of parameterizations with more accuracy. These three sites correspond to semi-arid and intermediate basins, and should therefore allow for some improvements in the parameterizations of surface, rootzone and deep-soil infiltration. Reinfiltration in ponds may also be adressed with the observations from the Niamey super-site in which pond systems are of major importance. Finally, floodplain parameterizations will benefit from the ongoing satellite observations of the floodplains' size (Prigent et al., 2007) and height (Gennero et al., 2006).

At larger scale, the AMMA field experiment also covers the gradient between the guinean and the saharian regions through a transect around the Greenwich meridian. Work accross scales with different types of modelling and observations at different scales should help to improve the parameterizations cited above (Boone and de Rosnay, 2007). So, the AMMA project should increase our knowledge by giving more insight into the link between various scales involved in surface-atmosphere feedbacks and by offering a means to validate regional parameterizations of small scale processes.

Acknowledgements. We wish to thank Alain Perrier and Guy Richard for helpful disussions on ORCHIDEE developments. We also thank Thanh Ngo-Duc for his help on ORCHIDEE simulations, and Anne-Charlotte Vivant for her initial work on floodplains in ORCHIDEE. We finally thank Paul Dirmeyer for his initial help with GSWP2 simulations and Sharon Sterling for her precious advices on the use of vegetation maps. This work has been conducted with R (R Development Core Team, 2003). This research was done within the AMMA framework. Based on a French initiative, AMMA was built by an international scientific group and is currently funded by a large number of agencies, especially from France, EU, US and Africa. It has been the beneficiary of a major financial contribution from the European Community's Sixth Framework Research Programme. Detailed information on scientific coordination and funding is available on the AMMA International web site http://www.amma-international.org.

Edited by: J. D. Kalma

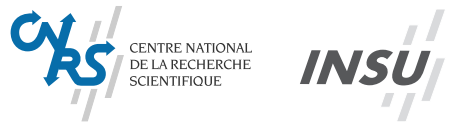

The publication of this article is financed by CNRS-INSU.

\section{References}

Beven, K.: Macropores and water flow in soils, Water Resour. Res., 18, 1311-1325, 1982.

Beven, K.: Infiltration into a class of vertically non uniform soils, Hydrolog. Sci. J., 29, 1425-434, 1984.

Bonan, G., Oleson, K., Vertenstein, M., Levis, S., Zeng, X., Dai, Y., Dickinson, R., and Yang, Z.-L.: The land surface climatology of the Community Land Model coupled to the NCAR Community Climate Model, J. Climate, 15, 3123-3149, 2002.

Boone, A. and de Rosnay, P.: AMMA forcing data for a better understanding of the West African monsoon surface-atmospherehydrology interactions. Quantification and Reduction of Predictive Uncertainty for Sustainable Water Resource Management, in: IAHS Publ. proceeding, vol. 313, 2007.

Cappelaere, B., Vieux, B., Peugeot, C., Maia, A., and Séguis, L.: Hydrologic process simulation of a semiarid, endoreic catchment in Sahelian West Niger. 2. Model calibration and uncertainty characterization, J. Hydrol., 279, 244-261, 2003. 
Carsel, R. and Parrish, R.: Developing joint probability distributions of soil water retention characteristics, Water Resour. Res., 24, 755-769, 1988.

Chen, J. and Kumar, P.: Topographic influence on the seasonal and interannual variation of water and energy balance of basins in North America, J. Climate, 14, 1989-2014, 2001.

de Rosnay, P. and Polcher, J.: Improvements of the representation of the hydrological exchanges between the biosphere and the atmosphere in a GCM, Hydrol. Earth Syst. Sci., 2, 239-256, 1998, http://www.hydrol-earth-syst-sci.net/2/239/1998/.

de Rosnay, P., Bruen, M., and Polcher, J.: Sensitivity of surface fluxes to the number of layers in the soil model used in GCMs, Geophys. Res. Lett., 27, 3329-3332, 2000.

de Rosnay, P., Polcher, J., Bruen, M., and Laval, K.: Impact of a physically based soil water flow and soil-plant interaction representation for modeling large scale land surface processes, J. Geophys. Res., 107(D11), 4118, doi:2001JD000 634, 2002.

Decharme, B. and Douville, H.: Introduction of a sub-grid hydrology in the ISBA land surface model, Clim. Dynam., 26, 65-78, 2006.

Decharme, B., Douville, H., Boone, A., Habets, F., and Noilhan, J.: Impact of an Exponential Profile of Saturated Hydraulic Conductivity within the ISBA LSM: Simulations over the Rhône Basin., J. Hydrometeorol., 7, 61-80, 2006.

Dirmeyer, P. and Zeng, F.: An update to the distribution and treatment of vegetation and soil properties in SSiB, Tech. Rep. COLA Tech. Report, Center for Ocean-Land-Atmosphere, 25 pp., 1999.

Dirmeyer, P., Gao, X., and Oki, T.: The second Global Soil Wetness Project science and implementation plan, Tech. Rep. IGPO Publ. Series, Int. Global Energy and Water Cycle Exp. (GEWEX) Project Office, Silver Spring, Md., 65 pp., 2002.

Dirmeyer, P., Gao, X., Zhao, M., Guo, Z., Oki, T., and Hanasaki, N.: The second Global Soil Wetness Project (GSWP-2): Multimodel analysis and implications for our perception of the land surface, B. Am. Meteorol. Soc., 87, 1381-1397, 2006.

d'Orgeval, T.: Impact du changement climatique sur le cycle de l'eau en Afrique de l'Ouest: Modélisation et Incertitudes, Ph.D. thesis, Université Paris VI, 188 pp., 2006.

d'Orgeval, T. and Polcher, J.: Impacts of precipitation events and land-use changes on West African river discharges during the years 1951-2000, Clim. Dynam., 31, 249-262, 2008.

Ek, M., Mitchell, K., Lin, Y., Grunmann, P., Rogers, E., Gayno, G., Koren, V., and Tarpley, J.: Implementation of the upgraded NOAH land-surface model in the NCEP operational mesoscale Eta model, J. Geophys. Res., 108, 8851, doi:10.1019/2002JD003 296, 2003.

Essery, R., Best, M., Betts, R., Cox, P., and Taylor, C.: Explicit representation of subgrid variability in the GCM land surface scheme, J. Hydrometeorol., 4, 530-543, 2003.

Etchevers, P., Colaz, C., and Habets, F.: Simulation of the water budet and the rivers flows of the Rhône basin from 1981 to 1994 , J. Hydrol., 244, 60-85, 2001.

Fekete, B. M., Vorosmarty, C., and Grabs, W.: Global, Composite Runoff Fields Based on Observed River Discharge and Simulated Water Balances, Tech. rep., UNH/GRDC, Global Runoff Data Centre, Koblenz, Germany, 2000.
Food and Agriculture Organization: Soil map of the world, scale 1:5000000, Tech. rep., United Nations, volumes I-X, United Nations Educationnal, Scientific and Cultural Organization, Paris, 1978.

Gennero, M., Crétaux, J., Bergé-Nguyen, M., Maheu, C., Do Minh, K., Calmant, S., and Cazenave, A.: Surface water monitoring by satellite altimetry, http://www.legos.obs-mip.fr/soa/hydrologie/ hydroweb/, 2006.

Goutorbe, J.-P., Lebel, T., Tinga, A., Bessemoulin, P., Brouwer, J., Dolman, A. J., Engman, E. T., Gash, J. H. C., Hopffner, M., Kabat, P., Kerr, Y. H., Monteny, B., Prince, S., Said, F., Sellers, P., and Wallace, J. S.: HAPEX-Sahel: a large-scale study of landatmosphere interactions in semi-arid tropics., Ann. Geophys., 12, 53-64, 1994, http://www.ann-geophys.net/12/53/1994/.

Guo, Z., Dirmeyer, P., Koster, R., Bonan, G., Chan, E., Cox, P., Gordon, C., Kanae, S., Kowalczik, E., Lawrence, D., Liu, P., Lu, C.-H., Malyshev, S., McAvaney, B., McGregor, J., Mitchell, K., Mocko, D., Oki, T., Oleson, K., Pitman, A., Sud, Y., Taylor, C., Verseghy, D., Vasic, R., Xue, Y., and Yamada, T.: GLACE: The Global Land-Atmosphere Coupling Experiment. Part II: Analysis, J. Hydrometeorol., 7, 611-625, 2006.

Gusev, Y. and Nasonova, O.: The simulation of heat and water exchange in the boreal spruce forest by the land-surface model SWAP, J. Hydrol., 280, 162-191, 2003.

Hagemann, S., Botzet, M., Dümenil, L., and Machenhauer, B.: Derivation of global GCM boundary conditions from $1 \mathrm{~km}$ land use satellite data, Report, Max-Planck-Institut für Meteorologie, Hamburg, Report No. 289, 34 pp., 1998.

Kalnay, E., Kanamitsu, M., Kistler, R., Collins, W., Deaven, D., Gandin, D., Iredella, M., Saha, S., White, G., Woolen, J., Zhu, Y., Leetma, A., and Reynolds, B.: The NCEP-NCAR 40-year reanalysis project, B. Am. Meteorol. Soc., 77, 437-471, 1996.

Kanamitsu, M., Ebisuzaki, W., Woollen, J., and Yang, S.: NCEP/DOE AMIP-II Reanalysis (R-2), B. Am. Meteorol. Soc., 93, 1631-1643, 2002.

Koster, R. D. and Suarez, Max, J.: Modeling the Land surface boundary in climate models as a composite of independent vegetation stands, J. Geophys. Res., 97, 2697-2715, 1992.

Koster, R., Suarez, M., Ducharne, A., Praveen, K., and Stieglitz, M.: A catchement-based approach to modelling land-surface processes in a GCM - Part 1: Model structure, J. Geophys. Res., 105(D20), 24 809-24 822, 2000.

Koster, R. D., Dirmeyer, P. A., Guo, Z., Bonan, G., Chan, E., Cox, P., Gordon, C. T., Kanae, S. Kowalczyk, E., Lawrence, D., Liu, P., Lu, C.-H., Malyshev, S., McAvaney, B., Mitchell, K., Mocko, D., Oki, T., Oleson, K., Pitman, A., Sud, Y. C., Taylor, C. M., Verseghy, D., Vasic, R., Xue, Y., and Yamada, T.: Regions of strong coupling between soil moisture and precipitation, Science, 305, 1138-1140, 2004.

Koster, R., Guo, Z., Dirmeyer, P., Bonan, G., Chan, E., Cox, P., Davies, H., Gordon, C., Kanae, S., Kowalczik, E., Lawrence, D., Liu, P., Lu, C.-H., Malyshev, S., McAvaney, B., Mitchell, K., Mocko, D., Oki, T., Oleson, K., Pitman, A., Sud, Y., Taylor, C., Verseghy, D., Vasic, R., Xue, Y., and Yamada, T.: GLACE: The Global Land-Atmosphere Coupling Experiment. Part I: Overview, J. Hydrometeorol., 7, 590-610, 2006. 
Krinner, G., Viovy, N., De Noblet-Ducoudré, N., Ogée, J., Polcher, J., Friedlingstein, P., Ciais, P., Stitch, S., and Prentice, C.: A dynamic global vegetation model for studies of the coupled atmosphere-biosphere system, Global Biogeochem. Cy., 19, GB1015, doi:10.1029/2003GB002199, 2005.

Le Barbé, L., Lebel, T., and Tabsoba, D.: Rainfall Variability in West Africa during the years 1950-1990, J. Climate, 15, 187202, 2002

Lehner, B. and Doll, P.: Development and validation of a global database of lakes, reservoirs and wetlands, J. Hydrol., 296, 1-22, 2004.

Manabe, S.: Climate and the ocean circulation 1. The atmospheric circulation and the hydrology of the earth's surface, Mon. Weather Rev., 97, 739-774, 1969.

Miller, J. R., Russell, G. L., and Caliri, G.: Continental-Scale River Flow in Climate Models., J. Climate, 7, 914-928, 1994.

Milly, P. and Shmakin, A.: Global modeling of land water and energy balances. Part I: The land dynamics (LaD) model, J. Hydrometeorol., 3, 283-299, 2002.

Mocko, D. and Sud, Y.: Refinements to SSiB with an emphasis on snow-physics: Evaluation and Validation using GSWP and Valdaï data, Earth Interactions, 5, 31 pp., 2001.

Monsi, M. and Saeki, T.: Über den Lichtfaktor in den Pflanzengesellschaften und seine Bedeutung für die Stoffproduktion, Jpn. J. Bot., 14, 22-52, 1953.

Mualem, Y.: A new model for predicting the hydraulic conductivity of unsaturated porous media, Water Resour. Res., 12, 513-522, 1976.

New, M., Hulme, M., and Jones, P. D.: Representing twentieth century space-time climate variability. Part 2: Development of 1901-1996 monthly grids of terrestrial surface climate, J. Climate, 13, 2217-2238, 2000.

Ngo-Duc, T., Polcher, J., and Laval, K.: A 53-year forcing data set for land surface models, J. Geophys. Res., 110, D06 116, doi:10.1029/2004JD005 435, 2005.

Ngo-Duc, T., Laval, K., Ramillien, G., and Polcher, J.: Validation of the land water storage simulated by ORCHIDEE with GRACE data: role of the routing scheme, Water Resour. Res., 43, W04 427, doi:2006WR004 941, 2007.

Oki, T., Nishimura, T., and Dirmeyer, P.: Assessment of Land Surface Models by runoff in major river basins of the globe using Total Runoff Integrating Pathways (TRIP), J. Meteorol. Soc. Jpn., 77, 235-255, 1999.
Peugeot, C., Cappelaere, B., Vieux, B., Séguis, L., and Maia, A.: Hydrologic process simulation of a semiarid, endoreic catchment in Sahelian West Niger. 1. Model aided data analysis and screening, J. Hydrol., 279, 224-243, 2003.

Prigent, C., Matthews, E., Aires, F., and Rossow, W.: Remote sensing of global wetland dynamics with multiple satellite datasets, Geophys. Res. Lett., 24, 4631-4634, 2001.

Prigent, C., Papam, F., Aires, F., Rossow, W., and Matthews, E.: Global inundation dynamics inferred from multiple satellite observations, 1993-2000, J. Geophys. Res., 112, D12107, doi:10.1029/2006JD007847, 2007.

R Development Core Team: R: A language and environment for statistical computing, R Foundation for Statistical Computing, Vienna, Austria, http://www.R-project.org, ISBN 3-900051-003, 2003.

Reynolds, C., Jackson, T., and Rawls, W. J.: Estimating Available Water Content by Linking the FAO Soil Map of the World with Global Soil Profile Databases and Pedo-transfer Functions, in: Proceedings of the AGU 1999 Spring Conference, Boston, MA, 1999.

Sterling, S. and Ducharne, A.: Comprehensive data set of global land cover change for land surface model applications, Global Biogeochem. Cy., 22, GB3017, doi:10.1029/2007GB002959, 2006.

Stieglitz, M., Rind, D., Famiglietti, J., and Rosenzweig, C.: An efficient approach to modeling the topographic control of surface hydrology for regional and global climate modeling, J. Climate, 10, 118-137, 1995.

Van Genuchten, M.: A closed-form equation for predicting the hydraulic conductivity of unsaturated soils, Soil Sci. Soc. Am. J., 44, 892-898, 1980.

Yang, Z.-L. and Niu, G.-Y.: The versatile integrator of surface and atmosphere processes (VISA), Part I: Model description, Global and Planetary Change, 38, 175-189, 2003.

$\mathrm{Yu}, \mathrm{Z}$ : : Assessing the response of sub-grid hydrologic processes to atmospheric forcing with a hydrologic model system, Global Planet. Change, 25, 1-17, 2003.

Zeng, N., Mariotti, A., and Wetzel, P.: Mechanisms of interannual CO2 variability, Global. Biogeochem. Cy., 19, GB1016, doi:10.1019/2004GB002 273, 2005.

Zobler, L.: A world soil file for global climate modeling, Tech. rep., NASA tech. Memo. 87802, 1986 